\title{
Do Immaturity, Dehydratation or Alkalosis Predispose to Intraoperative Complications at Pyloromyotomy?
}

\author{
Ralf-Bodo Tröbs*, Lars Burghardt, Micha Bahr, Matthias Nissen \\ Department of Pediatric Surgery Clinic, Marien Hospital Herne, St. Elisabeth Gruppe, Ruhr-Universität Bochum, Herne, Germany \\ Email: ${ }^{*}$ ralf-bodo.troebs@elisabethgruppe.de
}

How to cite this paper: Tröbs, R.-B., Burghardt, L., Bahr, M. and Nissen, M. (2016) Do Immaturity, Dehydratation or Alkalosis Predispose to Intraoperative Complications at Pyloromyotomy? Open Journal of Pediatrics, 6, 203-212.

http://dx.doi.org/10.4236/ojped.2016.63029

Received: June 17, 2016

Accepted: August 6, 2016

Published: August 9, 2016

Copyright $(0) 2016$ by authors and Scientific Research Publishing Inc. This work is licensed under the Creative Commons Attribution International License (CC BY 4.0).

http://creativecommons.org/licenses/by/4.0/ (c) (7)

Open Access

\begin{abstract}
Background: Hypertrophic pyloric stenosis is the most important cause for propulsive non-bilious vomiting in infants of the first trimester. Extramucous splitting of the hypertrophic pyloric muscle is the surgical gold standard for treatment. Serious major complications of pyloromyotomy (PM) are mucosal perforation and incomplete muscle splitting. The aim of the presented study is to find out if intraoperative complications are predisposed by biometric or biochemical factors. Furthermore, we looked for the influence of the board certification of the primary surgeon. Patients and Methods: 162 infants with IHPS were operated during a six-year period ( $n=150$ laparoscopic operations). We had 8 major complications (4.9\%): iatrogenic mucosal perforation occurred in 6 cases, and incomplete PM in 2 infants. Preoperative demographic data and data resulting from the blood acid-base- and ion-analysis were compared with data of a previously published reference group from our institution (Tröbs RB. Open J Pediatr, 2014; 4: 208-215). Results: The duration of vomiting, the grade of dehydration and the severity of blood alkalosis did not differ between both groups. Furthermore, we found no influence of the gestational age and birth weight on the occurrence of intraoperative complications. It seems that early postnatal age $(\mathrm{p}=0.07)$ and low body weight at surgery $(\mathrm{p}=0.055)$ may contribute to surgical problems. Board certification as a paediatric surgeon did not influence the rate of intraoperative complications. Conclusions: Laboratory data did not show any predisposition to intraoperative complications. It is assumed that small infants with early occurring symptoms carry an elevated risk for intraoperative events. Our data support the hypothesis that the rate of intraoperative complications at PM is mainly influenced by skills and experience of the surgeon.
\end{abstract}

\section{Keywords}

Hypertrophic Pyloric Stenosis, Pyloromyotomy, Complication, Perforation, 
Alkalosis, Surgical Training

\section{Introduction}

Infantile Hypertrophic Pyloric Stenosis (IHPS) is a typical disorder of infants in the first trimester. The principle symptom is projectile non-bilious vomiting of partially digested milk shortly after feeding [1]. The cause of this occurrence is a hypertrophy of the musculature of the pylorus. In consequence of the absent passage of fluids and food, dehydration and catabolic metabolism occur. The loss of gastric acid causes hypopotassemic alkalosis [2]-[4]. Particularly with a case history of more than one week, serious disturbances in homeostasis are to be expected [5].

It is assumed that "idiopathic" hypertrophy of the pyloric muscle is initiated with the beginning of oral ingestion after the birth. Those most commonly affected are term male infants aged 4 to 6 weeks. In addition, firstborns and bottle-fed infants are particularly predestined [6]. The case history, the characteristic clinical data and ultrasound diagnosis allow a timely and certain preoperative diagnosis [7] [8]. Therapy for IHPS is primarily surgical. It occurs according to the principle of extramucous splitting of the hypertrophic pyloric muscle. This method is distinguished by high reliability and a high rate of success. However, serious complications such as mucosal perforation or incomplete splitting of the pylorus cannot always be avoided. With the introduction of the laparoscopic pyloromyotomy, and after the method was broadly established, the significance of a learning curve for the reliable and quick performance of the operation became clear [9]-[12]. However, previous studies did not consider the question of the influence of biometric or biochemical factors on major complications.

This question is asked by the present study.

\section{Patients, Material, and Methods}

The population of all infants operated on due to IHPS in our teaching hospital between January 2009 and August 2015 was retroactively recorded. The data collection occurred using both the clinical documents and the operation reports. Children that suffered a mucosal perforation or an incomplete pyloromyotomy were aggregated into the group Complicative.

The biometric and biochemical parameters were compiled using routine diagnostics on the occasion of inpatient admission of the children and before infusion therapy. We compared the date of the Complicative group with an independently published normal group of 56 children from our department [13].

The same analysis device was used for both the verum group and the comparison group (GEM Premier $4000^{\circledR}$-Device, Instrumentation Laboratory, Lexington, MA, USA).

In $4 / 5$ of the cases, capillary blood was analyzed. Systematic differences between cap- 
illary and venous blood samples could not be recorded. This is subject to constant quality control in the course of the legally prescribed ring trial.

\section{Operation}

We primarily performed the operation laparoscopically with a three trocar technique. A minority of the children were operated on using the conventional open, right side incision on the upper abdomen. In cases of mucosal perforation, the open stitching of the mucosa occurred after conversion. In the event of incomplete splitting, an open revision also occurred.

\section{Data Analysis}

We applied the median value and the arithmetic mean. In addition, we indicated the respective minimum or maximum. For the graphical depiction of the data sets, box plots and whisker plots were used.

Testing using the Kolmogorov-Smirnov test on the 0.05 significance level resulted in normal distribution for all data sets. For significance testing, we used the 2 sample $\mathrm{t}$-test. A statistically significant difference were classified as $\mathrm{p} \leq 0.05$.

\section{Ethics Rating}

The study has been approved by the ethics commission of the medical faculty of Ruhr University (Register No. 16-5604).

\section{Results}

In total, 162 infants were operated during the study period, 150 laparoscopically. In 8 cases $(4.9 \%$ of the population), major complications occurred. Iatrogenic mucosal perforation occurred in 6 cases (3.7\% of the population) and incomplete pyloromyotomy in 2 cases (1.2\% of the population). With one exception, all complications occurred in laparoscopic operations. In 5 children, the operation was performed by a specialist in pediatric surgery, and in 3 cases, by a doctor in pediatric surgical training.

The biometric data of the Complicative group is compared to the control group in Table 1 and the initial biochemical values are compared to the control group in Table 2.

\section{Statistical differences are shown in Table 3.}

For the Complicative group, we found a lower age at the time of the operation (median/mean value 28 or 31 days) in comparison to the control group (37 or 39 days). This corresponded with a lower weight on entry (median/mean value 3.5 or $3.4 \mathrm{~kg}$ versus (vs.) 3.8 or $4.0 \mathrm{~kg}$ ). In addition, there were higher haemoglobin concentrations in the group with complications (median/mean value 14 or $13.7 \mathrm{~d} / \mathrm{dl}$ vs. 12.8 or $13 \mathrm{~g} / \mathrm{dl}$ ), as well as higher haematocrit values (median/mean value $42 \%$ or $40 \%$ vs. $38 \%$ or $40 \%$ ). The sodium concentrations in the blood were almost identical. Concerning moderately pronounced alkalosis, there was also an almost identical value of blood $\mathrm{pH}$ and of the standard bicarbonate in less pronounced chloride loss in the verum group (median/ 
Table 1. Biometric data in comparison (median [arithmetic average], minimum - maximum).

\begin{tabular}{ccc}
\hline Parameter & Complicative & Control [Tröbs et al., 2014] \\
\hline Number of children & 8 & 56 \\
Male:female & $8: 0$ & $4: 1$ \\
Gestational age & $39[37]$ & $38[38]$ \\
[weeks] & $33-40$ & $33-41$ \\
& $3.1[2.9]$ & $3.2[3.3]$ \\
Weight at birth [kg] & $1.7-4.0$ & $(2-4.4)$ \\
& $28[31]$ & $37[39]$ \\
Age at operation [days] & $19-50$ & $18-108$ \\
& $4[4]$ & $4[6]$ \\
Vomiting [days] & $1-6$ & $1-28$ \\
Body weight & $3.5[3.4]$ & $3.8[4.0]$ \\
[kg] & $2.3-4.2$ & $2.7-5.9$
\end{tabular}

Table 2. Laboratory parameters in comparison (median [arithmetic average], minimum - maximum).

\begin{tabular}{|c|c|c|}
\hline Parameter & Complicative & Control \\
\hline \multirow{2}{*}{ Haemoglobin [g/dlt-test] } & $14[13.7]$ & $12.8[13.0]$ \\
\hline & $10.9-19.3$ & $9.1-17.8$ \\
\hline Haematocrit & $42[40]$ & $37[38]$ \\
\hline [\%] & $31-56$ & $27-55$ \\
\hline \multirow{2}{*}{$\begin{array}{l}\text { Potassium } \\
{[\mathrm{mmol} / \mathrm{l}]}\end{array}$} & $138[137]$ & $137[137]$ \\
\hline & $134-139$ & $130-144$ \\
\hline \multirow{2}{*}{$\begin{array}{l}\text { Chloride } \\
{[\mathrm{mmol} / \mathrm{l}]}\end{array}$} & $110[103]$ & $101[98]$ \\
\hline & $91-111$ & $83-108$ \\
\hline \multirow{2}{*}{$\mathrm{pH}$} & $7.5[7.5]$ & $7.5[7.5]$ \\
\hline & $7.45-7.56$ & $7.32-7.65$ \\
\hline \multirow{2}{*}{$\begin{array}{c}\text { Standard bicarbonate } \\
{[\mathrm{mmol} / \mathrm{l}]}\end{array}$} & $28.5[30.0]$ & $27.9[28.7]$ \\
\hline & $26.9-33.6$ & $21.0-41.0$ \\
\hline \multirow{2}{*}{ Base excess $[\mathrm{mmol} / \mathrm{l}]$} & $5[6.8]$ & $3.8[5.2]$ \\
\hline & $3.8-12.8$ & $-4-17.9$ \\
\hline $\mathrm{pCO}_{2}$ & $5.5[5.7]$ & $5.7[5.7]$ \\
\hline$[\mathrm{kPa}]$ & $4.8-6.5$ & $3.7-8.4$ \\
\hline Glucose & $3.7[4.1]$ & $5.05[5.11]$ \\
\hline$[\mathrm{mmol} / \mathrm{l}]$ & $3.0-5.6$ & $4.0-6.7$ \\
\hline Lactate & $2.0[2.1]$ & $1.8[2.0]$ \\
\hline$[\mathrm{mmol} / \mathrm{l}]$ & $1.2-3.5$ & $0.8-3.9$ \\
\hline
\end{tabular}


Table 3. p-values for selected parameters (t-test).

\begin{tabular}{ccc}
\hline Parameter & p-values & N1; N2 \\
Birth weight & 0.21 & $47 ; 8$ \\
Gestational age & 0.62 & $37 ; 9$ \\
Weight at entry & 0.055 & $51 ; 8$ \\
Age at OP & 0.07 & $52 ; 8$ \\
Haemoglobin concentration & 0.15 & $50 ; 8$ \\
Haematocrit & 0.32 & $49 ; 7$ \\
Chloride & 0.09 & $21 ; 8$ \\
Base excess & 0.40 & $51 ; 7$ \\
Standard bicarbonate & 0.40 & $47 ; 7$ \\
Carbon dioxide partial pressure & 0.60 & $50 ; 7$ \\
Lactate & 0.96 & $27 ; 6$ \\
Glucose & 0.0001 & $46 ; 7$ \\
\hline
\end{tabular}

N1; N2 sample size: Complicative vs. comparison group.

mean value 110 or 103 vs. 101 or $98 \mathrm{mmol} / \mathrm{l})$. For blood glucose, there was surprisingly a highly significant reduction in the Complicative group (median/mean value 3.7 or 4.1 vs. 5.05 or 5.11). The concentrations of lactate were essentially the same.

\section{Discussion}

The pathogenesis of IHPS has been illuminated in key aspects in the past two decades. Hyperacidity of the stomach acid in consequence of passage hypergastrinemia or a defect in nitrogen oxide production in the pylorus have particularly been discussed in clarifying the muscular hypertrophy of the pylorus [14] [15].

A higher incidence of IHPS in males of approximately 4:1 [1] [6]-[18] has always been reproducible. The exclusive prevalence of male infants in the Complicative group is thus easily explained.

\section{Biometric Parameters}

Only a minority of the infants with IHPS were preterm [19]. In our historical control group, $25 \%$ of the children were born before the $37^{\text {th }}$ week of pregnancy and were thus preterm. In correspondence with this, $25 \%$ of the infants with complications were born preterm. Our data might indicate a difference between the gestational age of both groups $(\mathrm{p}=0.62)$. Three infants from the Complicative group had a lower birth weight between 1500 and $2500 \mathrm{~g}$ (low birth weight), but a significant difference in the birth weight did not exist $(\mathrm{p}=0.21)$. On the occasion of the operation, the body weight of the Complicative group was less than the weight of the comparison group $(\mathrm{p}=0.055)$ (Figure 1). A lower postnatal age was also noticeable in the Complicative group ( $\mathrm{p}=$ 0.07 ), which is to say that symptoms began earlier and the operation occurred at a par- 
ticularly early age of a median of 28 days, in comparison to 37 days in the comparison group (Figure 2).

\section{Acid-Base- and Ion-Analysis}

It is well known that loss of gastric juices and dehydration significantly influence the balance of acids, bases, and ions in IHPS. With increasing dehydration, there is a trend of decreasing sodium, potassium and particularly chloride in the blood, and the concentration of bicarbonate increases [5] [8] [20] [21].

The median duration of non-bilious preoperative vomiting was comparatively short: it was 4 days for both groups. The result was generally a moderate alkalosis, with both groups having the same median and mean $\mathrm{pH}$ value of 7.5. The base excess (shows the metabolic components of disturbances of acids/bases/ions), as well as the bicarbonate, moved in identical increased ranges (both $\mathrm{p}=0.40$ ). The respiratory side of the acid/base balance, represented by the partial pressure of carbon dioxide $\left(\mathrm{pCO}_{2}\right)$ was on

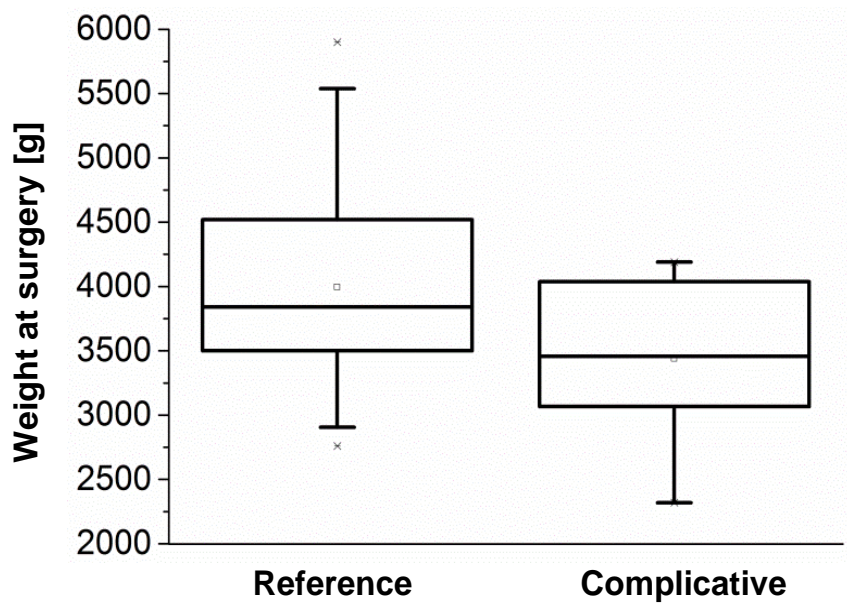

Figure 1. Comparison of body weight on the occasion of inpatient admission for the operation ( $p$ $=0.055)$.

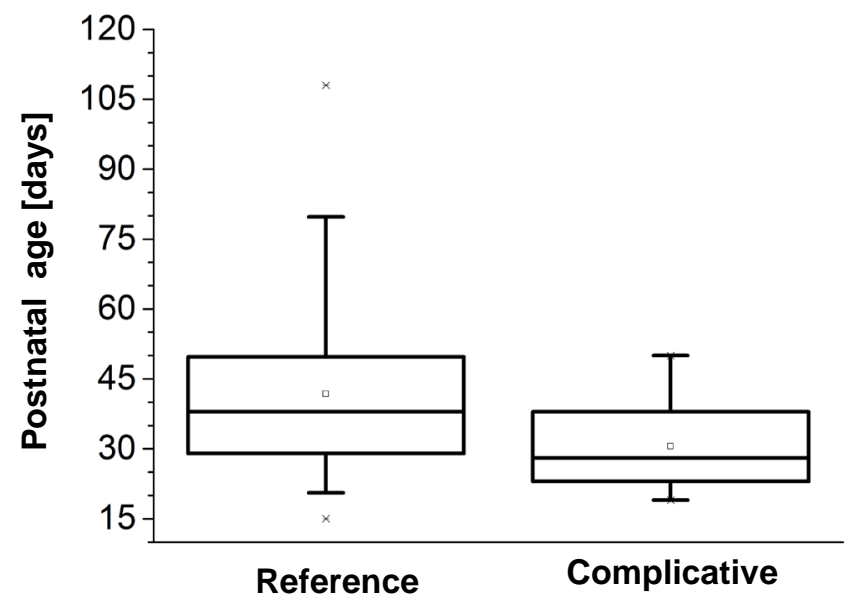

Figure 2. Postnatal age at operation $(\mathrm{p}=0.07)$. 
average in the normal range ( $4.5-6.5 \mathrm{kPa})$ with 5.5 to $5.7 \mathrm{kPa}(\mathrm{p}=0.60)$. We only observed a measurable respiratory depression in one patient of the comparison group [13] [22] [23]. The lactate as a measure of anaerobic metabolism and liver clearance were also the same for both groups $(\mathrm{p}=0.96)$.

In our previous study, we were able to show that a statistically significant negative correlation between haemoglobin concentration in the blood and the postnatal age exists for infants with IHPS [13]. Smaller infants with a time interval from the nadir of trimester anaemia still showed higher haemoglobin. In correspondence with this, our younger Complicative group showed a higher concentration of haemoglobin $(p=0.15)$ in comparison with our older comparison group, as well as a higher haematocrit ( $\mathrm{p}=$ 0.32 ).

The bicarbonate concentrations, pivot point of the metabolic alkalosis and indicator of the degree of dehydration [5] were equally great in both groups $(\mathrm{p}=0.40)$. If the encountered values for haematocrit, bicarbonate and potassium $(137 \mathrm{mmol} / \mathrm{l}$ for both groups) are interpreted, moderate dehydration can be assumed for both groups.

The lower glucose concentrations in the Complicative group, which are significant in comparison ( $\mathrm{p}=0.0001$ ), indicate a beginning exhaustion of the glycogen stores and deficient gluconeogenesis with insufficient carbohydrate supply. A tendency to hypoglycaemia is well known in infants with IHPS [24]-[26].

However, critical glucose values below the reference area of $2.6-6.6 \mathrm{mmol} / \mathrm{l}$ were not found in any group.

\section{Complications}

With the introduction of laparoscopic pyloromyotomy, particularly great attention was dedicated to the study of methodical and subjective factors in the emergence of intraoperative complications. Particular advantages of laparoscopic pyloromyotomy are the quicker postoperative development of nutrition and a shorter time spent in hospital [9] [27]. It was particularly shown that the introduction of the laparoscopic method was afflicted with a learning curve [10] [11]. After the establishment of the method, a detailed metaanalysis showed that there were no systematic differences regarding the rate of mucosa perforation, operating time, or the duration of postoperative vomiting between the use of the open or the laparoscopic procedure [27]. According to a survey of members of the International Paediatric Endosurgical Group (IPEG), mucosa perforations occurred at the same rate in open and laparoscopic pyloromyotomies [28]. In a multicenter study on 2,830 cases, there was shown to be an increased risk of an incomplete pyloromyotomy in a laparoscopy [29]. Our task force recently published an algorithm for the avoidance of incomplete pyloromyotomies [30].

In a synopsis of the rates of complications in laparoscopic pyloromyotomies, the rate of perforations in the pylorus or duodenum area was rated at 5\% to $20 \%$ (3.7 in the presented series) [31]. The frequency of an incomplete muscle splitting or return of the pyloric obstruction was calculated at $1 \%$ to $5 \%$ (1.2 in the presented series) [31]. In the course of the learning curve, the total complication rate for laparoscopic pyloro- 
myotomy in a series could be reduced from $31.5 \%$ to $11.4 \%$ (major and minor complications) [11].

The fact of a temporal cluster concerning major complications in our series is interesting. This temporary "cluster" seemed to be connected with a change in clinic personnel. This underscores the importance of subjective influences on the process quality of the operation. The 5:3 relationship between specialists and doctors in surgical training as first surgeon closely reflects the division of pyloromyotomies between the two qualification groups in our clinic, meaning that the rate of complications is not dependent on specialist status. Rather it must be born in mind that process and results quality is significantly influenced by both participating surgeons.

\section{Limitations of the Study}

IHPS manifests in Germany with a prevalence of 2.3 cases per 1,000 births [16], meaning that approximately 1,500 cases are to be expected in Germany per year. The present study was limited to a patient series in a single institution. With a major complication rate of below 5\%, the Complicative group was naturally small. Significances therefore necessarily only resulted from severe differences. Given these aspects, the present study should be considered to be a pilot.

\section{Conclusion}

Laboratory data did not indicate any predisposition to intraoperative complications. It is assumed that smaller infants carry an elevated risk for complications. In cooperation with an experienced board certified surgeon, laparoscopic pyloromyotomy is an appropriate operation for surgical training in the field of pediatric surgery.

\section{References}

[1] Georgoula, C. and Gardiner, M. (2012) Pyloric Stenosis a 100 Years after Ramstedt. Archives of Disease in Childhood, 97, 741-746. http://dx.doi.org/10.1136/archdischild-2011-301526

[2] Tan, S. and Campbell, M. (2008) Acid-Base Physiology and Blood Gas Interpretation in the Neonate. Paediatrics and Child Health, 18, 172-177. http://dx.doi.org/10.1016/j.paed.2007.12.013

[3] Clark, R.G. and Norman, J.N. (1964) Metabolic Alkalosis in Pyloric Stenosis. Lancet, 1, 1244-1245. http://dx.doi.org/10.1016/S0140-6736(64)91869-0

[4] Shanbhogue, L.K.R., Sikdar, T., Jackson, M., et al. (1992) Serum Electrolytes and Capillary Blood Gases in the Management of Hypertrophic Pyloric Stenosis. British Journal of Surgery, 79, 251-253. http://dx.doi.org/10.1002/bjs.1800790322

[5] Beasley, S.W., Hudson, I., Hok Pan, Y., et al. (1986) Influence of Age, Sex, Duration of Symptoms and Dehydration of Serum Electrolytes in Hypertrophic Pyloric Stenosis. Australian Paediatric Journal, 22, 193-197. http://dx.doi.org/10.1111/j.1440-1754.1986.tb00222.x

[6] Biggar, R.J., Fischer, T.K., Lindholm, M., et al. (2012) Bottle-Feeding and the Risk of Pyloric Stenosis. Pediatrics, 130, e943-949. http://dx.doi.org/10.1542/peds.2011-2785 
[7] Ein, S.H., Masiakos, P.T. and Ein, A. (2014) The Ins and Outs of Pyloromyotomy: What We Have Learned in 35 Years. Pediatric Surgery International, 30, 467-480. http://dx.doi.org/10.1007/s00383-014-3488-8

[8] Glatstein, M., Carbell, G., Boddu, S.K., et al. (2011) The Changing Clinical Presentation of Hypertrophic Pyloric Stenosis: The Experience of a Large, Tertiary Care Paediatric Hospital. Clinical Pediatrics, 50, 192-195. http://dx.doi.org/10.1177/0009922810384846

[9] Muensterer, O.J. (2014) Der Stellenwert der minimalinvasiven Chirurgie bei der Behandlung der Leistenhernie und Pylorusstenose. Zentralblatt für Chirurgie, 139, 600-606. http://dx.doi.org/10.1055/s-0034-1383245

[10] Ford, W.D., Crameri, J.A. and Holland, A.J. (1997) The Learning Curve for Laparoscopic Pyloromyotomy. Journal of Pediatric Surgery, 32, 552-554. http://dx.doi.org/10.1016/S0022-3468(97)90705-3

[11] Oomen, M.W.N., Hoekstra, L.T., Bakx, R., et al. (2010) Learning Curves for Paediatric Laparoscopy: How Many Operations Are Enough? The Amsterdam Experience with Laparoscopic Pyloromyotomy. Surgical Endoscopy, 24, 1829-1833. http://dx.doi.org/10.1007/s00464-010-0880-x

[12] Adibe, O.O., Nichol, P.F., Flake, A.W., et al. (2006) Comparison of Outcomes after Laparoscopic and Open Pyloromyotomy in a High-Volume Paediatric Teaching Hospital. Journal of Pediatric Surgery, 41, 1676-1678. http://dx.doi.org/10.1016/j.jpedsurg.2006.05.051

[13] Tröbs, R.B. (2014) Pathophysiology of Hypertrophic Pyloric Stenosis Revisited: The Use of Isotonic Fluid for Preoperative Infusion Therapy Is Supported. Open Journal of Pediatrics, 4, 208-215. http://dx.doi.org/10.4236/ojped.2014.43027

[14] Oue, T. and Puri, P. (1999) Smooth Muscle Cell Hypertrophy versus Hyperplasia in Infantile Hypertrophic Pyloric Stenosis. Pediatric Research, 45, 853-857. http://dx.doi.org/10.1203/00006450-199906000-00012

[15] Rogers, I.M. (2006) The True Cause of Pyloric Stenosis Is Hyperacidity. Acta Paediatrica, 95, 132-136. http://dx.doi.org/10.1111/j.1651-2227.2006.tb02197.x

[16] De Laffolie, J., Turial, S., Heckmann, M., Zimmer, K.-P. and Schier, F. (2012) Decline in Infantile Hypertrophic Pyloric Stenosis in Germany in 2000-2008. Pediatrics, 129, e901-e906. http://dx.doi.org/10.1542/peds.2011-2845

[17] Leong, M.M., Chen, S.C.C., Hsieh, C.S., et al. (2011) Epidemiological Features of Infantile Hypertrophic Pyloric Stenosis in Taiwanese Children: A Nation-Wide Analysis of Cases during 1997-2007. PLoS ONE, 6, e19404.

[18] Feng, Z., Nie, Y., Zhang, Y., et al. (2014) The Clinical Features of Infantile Hypertrophic Pyloric Stenosis in Chinese Han Population: Analysis from 1998 to 2010. PLoS ONE, 9, e88925. http://dx.doi.org/10.1371/journal.pone.0088925

[19] Czeizel, A. (1972) Birthweight Distribution in Congenital Pyloric Stenosis. Archives of Disease in Childhood, 47, 978-980. http://dx.doi.org/10.1136/adc.47.256.978

[20] Dawson, K.P. and Graham, D. (1991) The Assessment of Dehydration in Congenital Pyloric Stenosis. The New Zealand Medical Journal, 104, 162-163.

[21] Touloukian, R.J. and Higgins, E. (1983) The Spectrum of Serum Electrolytes in Hypertrophic Pyloric Stenosis. Journal of Pediatric Surgery, 18, 394-397. http://dx.doi.org/10.1016/S0022-3468(83)80188-2

[22] Pappano, D. (2011) Alkalosis-Induced Respiratory Depression from Infantile Hypertrophic Pyloric Stenosis. Pediatric Emergency Care, 27, 124. http://dx.doi.org/10.1097/PEC.0b013e318209af50 
[23] Tigges, C.R. and Bigham, M.T. (2012) Hypertrophic Pyloric Stenosis: It Can Take Your Breath Away. Air Medical Journal, 31, 45-48. http://dx.doi.org/10.1016/j.amj.2011.06.009

[24] Shumake, L.B. (1975) Postoperative Hypoglycemia in Congenital Hypertrophic Pyloric Stenosis. Southern Medical Journal, 68, 223-224.

[25] Henderson, B.M., Schubert, W.K., Hug, G. and Martin, L.W. (1968) Hypoglycemia with Hepatic Glycogen Depletion: A Postoperative Complication of Pyloric Stenosis. Journal of Pediatric Surgery, 3, 309-316. http://dx.doi.org/10.1016/0022-3468(68)90016-X

[26] Dutta, S., Lodha, R., Kabra, M., Deshpande, V. and Menon, P.S. (2000) Persistent Hyperinsulinemic Hypoglycemia with Pyloric Stenosis. Indian Pediatrics, 37, 890-893.

[27] Sola, J.E. and Neville, H.L. (2009) Laparoscopic vs Open Pyloromyotomy: A Systematic Review and Meta-Analysis. Journal of Pediatric Surgery, 44, 1631-1637. http://dx.doi.org/10.1016/j.jpedsurg.2009.04.001

[28] Waldron, L.S., St Peter, S.D. and Muensterer, O.J. (2015) Management and Outcome of Mucosal Injury during Pyloromyotomy. An Analytical Survey Study. Journal of Laparoendoscopic \& Advanced Surgical Techniques, 25, 1044-1046. http://dx.doi.org/10.1089/lap.2015.0117

[29] Hall, N.J., Eaton, S., Seims, A., et al. (2014) Risk of Incomplete Pyloromyotomy and Mucosal Perforation in Open and Laparoscopic Pyloromyotomy. Journal of Pediatric Surgery, 49, 1083-1086. http://dx.doi.org/10.1016/j.jpedsurg.2013.10.014

[30] Vahdad, M.R., Nissen, M., Semaan, A., et al. (2015) Can a Simplified Algorithm Prevent Incomplete Laparoscopic Pyloromyotomy? Journal of Pediatric Surgery, 50, 1544-1548. http://dx.doi.org/10.1016/j.jpedsurg.2014.12.004

[31] Ford, A., Hutson, J. and Coventry, B.J. (2014) Paediatric Abdominal Surgery. Laparoscopic Pyloromyotomy for Pyloric Stenosis. In: Coventry, B.J., Ed., Paediatric Surgery. Complications, Risks and Consequences, Springer-Verlag, London, 40-42.

Submit or recommend next manuscript to SCIRP and we will provide best service for you:

Accepting pre-submission inquiries through Email, Facebook, LinkedIn, Twitter, etc. A wide selection of journals (inclusive of 9 subjects, more than 200 journals)

Providing 24-hour high-quality service

User-friendly online submission system

Fair and swift peer-review system

Efficient typesetting and proofreading procedure

Display of the result of downloads and visits, as well as the number of cited articles Maximum dissemination of your research work

Submit your manuscript at: http://papersubmission.scirp.org/ 